\title{
Paracrine interactions of vascular endothelial growth factor and platelet-derived growth factor in endothelial and lung cancer cells
}

\author{
NIELS REINMUTH ${ }^{1,2}$, SONJA RENSINGHOFF ${ }^{1}$, MIRIAM RAEDEL ${ }^{1}$, NICOLE FEHRMANN $^{1}$, \\ CHRISTIAN SCHWÖPPE ${ }^{1}$, TORSTEN KESSLER ${ }^{1}$, GUIDO BISPING ${ }^{1}$, FRANK HILBERG ${ }^{3}$, \\ GERALD J. ROTH ${ }^{4}$, WOLFGANG BERDEL ${ }^{1}$, MICHAEL THOMAS ${ }^{2}$ and ROLF M. MESTERS ${ }^{1}$
}

\author{
${ }^{1}$ Department of Medicine/Hematology and Oncology and the IZKF Muenster, University of Muenster, Muenster, Germany; \\ ${ }^{2}$ Clinic for Thoracic Diseases, University of Heidelberg, Heidelberg, Germany; ${ }^{3}$ Boehringer Ingelheim Austria GmbH, \\ Vienna, Austria; ${ }^{4}$ Boehringer Ingelheim Pharma GmbH \& Co. KG, Biberach an der Riss, Germany
}

Received December 15, 2006; Accepted February 14, 2007

\begin{abstract}
While the effects of single growth factors on endothelial cells (ECs) have been extensively studied, the importance of induction of growth factors such as PDGF-BB (platelet derived growth factor) in ECs and its impact on tumor cell functions are only partly understood. Human umbilical vein endothelial cells (HUVECs) were cultured under serum-free conditions and stimulated by $20 \mathrm{ng} / \mathrm{ml}$ VEGF (vascular endothelial growth factor) or $20 \mathrm{ng} / \mathrm{ml} \mathrm{bFGF}$ (basic fibroblastic growth factor). As determined by real-time PCR, both VEGF and bFGF induced a significant (up to 4-fold) increase in PDGF-B RNA expression which was time- and dose-dependent $(\mathrm{p}<0.05)$. Similarly, conditioned medium (CM) from lung cancer cells (A549) which is known to contain multiple growth factors including VEGF and bFGF also induced PDGF-B RNA expression. Using ELISA assays, VEGF and bFGF significantly increased PDGF-BB protein secretion in HUVECs $(\mathrm{p}<0.01)$. By addition of BIBF 1000, a novel inhibitor of the VEGF and bFGF receptor kinases, the effect of VEGF on PDGF-B RNA induction was significantly antagonized $(p<0.01)$. Furthermore, we studied the biological significance of EC-derived PDGF-BB on lung cancer cells. Interestingly, HUVEC-derived CM significantly stimulated migration of A549 cells $(p<0.001)$ with a trend to further increased migration with the use of VEGF-stimulated (PDGF$\mathrm{BB}$ rich) $\mathrm{CM}(\mathrm{p}=0.2)$. Collectively, endothelial and lung cancer cells seem to interact via various paracrine pathways, e.g. by the reciprocal induction of VEGF and PDGF-BB. Thus, targeting key molecules would result in expression alterations
\end{abstract}

Correspondence to: Dr Niels Reinmuth, Department of Internal Medicine-Thoracic Oncology, Clinic for Thoracic Diseases, University of Heidelberg, Amalienstr. 5, D-69126 Heidelberg, Germany

E-mail: niels.reinmuth@thoraxklinik-heidelberg.de

Key words: angiogenesis, BIBF 1000, endothelial cells, intercellular signaling, migration of multiple factors and alter the biological functions of both stromal and tumor cells.

\section{Introduction}

The essential role of angiogenesis, the formation of new blood vessels from the preexisting vasculature, for the growth of solid tumors including non-small cell lung cancer (NSCLC) has been well documented (1). However, the induction of angiogenesis is a complex process that comprises a series of interlinked steps and is tightly regulated by a variety of angiogenic and anti-angiogenic factors (2). Furthermore, the new sprouts formed by endothelial cells (ECs) are highly susceptible to various apoptotic stimuli such as acidosis and hypoxia. With the attachment of perivascular cells such as pericytes and vascular smooth muscle cells (VSMCs), the ECs become less susceptible to apoptotic stimuli and more independent from the presence of survival factors $(2,3)$. The stabilization effect of perivascular cells on ECs is believed to be mediated by direct cell-cell adhesions or in a paracrine way by secretion of various cytokines $(3,4)$.

To date, vascular endothelial growth factor (VEGF) is still considered as one of the most potent angiogenic and EC survival factors, binding to two tyrosine kinase receptors (VEGFR-1 and VEGFR-2), which are found predominantly on the surface of vascular ECs (5). Various growth factors such as insulin-like growth factor-I (IGF-I) and PDGF-BB are able to induce VEGF in several cell types including cancer cells (6-8). By VEGF induction, the angiogenic process may be initiated. In addition, the platelet-derived growth factor (PDGF) has gained considerable interest in recent years. PDGF-BB, which seems to be the predominant isoform in most cell types including VSMCs, ECs and lung cancer cells $(9,10)$, is a growth factor for various cell types including tumor cells and modulates angiogenesis through several effects including induction of VEGF, induction of VSMC migration, and regulating the blood flow secondary to constriction of VSMCs $(11,12)$. The importance of PDGF-BB for migration of pericytes and VSMCs has been demonstrated in vivo where mice lacking PDGF-B also lack microvascular pericytes in various tissues with abnormal capillaries and formation of 
microaneurysms (13). As a result from these abnormalities, hemorrhages and edema occur when blood pressure increases.

While PDGF-BB is accepted as one important factor involved in tumor and stromal development, its regulating factors remain largely unknown. Only few data have been published regarding the induction of PDGF-BB by cytokines such as TGFß-1 and interleukin-2 in various cell lines (14). For example, transforming growth factor beta-1 (TGFß-1) was capable of inducing PDGF-B mRNA expression in colon cancer cells dependent on the differentiation grade of the cells (15). In contrast, TGFß-1 induced PDGF-B mRNA levels in both normal human pancreas and in pancreatic adenocarcinoma cell lines (16). Recently, we demonstrated that treatment of pericytes and VSMCs with PDGF-BB led to VEGF induction, which in turn enhanced EC survival in a paracrine manner (3). In addition to the effect of PDGF on VEGF induction, we hypothesized that, in turn, VEGF may also have an effect on PDGF-BB expression.

In the present study, we provide novel evidence that VEGF and lung cancer-derived conditioned medium (CM) induce PDGF-BB in ECs in a time- and dose-dependent manner, which could be blocked by inhibiting the VEGFR. In addition, EC-derived CM increased migration of A549 lung cancer cells which could be enhanced by the pre-stimulation of ECs with VEGF.

\section{Materials and methods}

Materials. Recombinant human VEGF-A, basic FGF and PDGF-BB were purchased from R\&D Systems, Inc. (R\&D Systems GmbH, Wiesbaden, Germany). The novel indolinone derivative BIBF 1000, a small molecule tyrosine kinase inhibitor, was provided by Boehringer-Ingelheim (Boehringer Ingelheim Pharma, Ingelheim, Germany). Previous studies have demonstrated that BIBF 1000 effectively inhibits the VEGF receptors 1 through 3 , PDGFR $\alpha$ and $\beta$ and FGF receptors 1 and 3 at a dose of $1 \mu \mathrm{M}$ (17).

Cell lines and culture conditions. A549 human lung cancer and human umbilical vein endothelial cells (HUVECs) were purchased from American Type Culture Collection (Manassas, VA) and were maintained in $10 \%$ and $15 \%$ FCS containing MEM, respectively $(3,7)$. Cell media and substitutes were purchased from PAA Laboratories GmbH (Cölbe, Germany). All in vitro experiments were performed at $80-90 \%$ confluence unless described otherwise. Cells were used at passages 3-8 after their receipt from the supplier.

VEGFR expression. Total RNA was isolated from subconfluent HUVECs and A549 cells growing in standard medium using RNeasy (Qiagen, Hilden, Germany). From $1 \mu \mathrm{g}$ of RNA, cDNA was synthesized for $1 \mathrm{~h}$ at $37^{\circ} \mathrm{C}$, using random hexamers and Moloney murine leukaemia virus reverse transcriptase (Promega, Heidelberg, Germany). The resulting cDNA was subjected to PCR with a thermal cycler $\left(94^{\circ} \mathrm{C}\right.$ for $1 \mathrm{~min}$, $57^{\circ} \mathrm{C}$ for $1 \mathrm{~min}$, and $72^{\circ} \mathrm{C}$ for $1 \mathrm{~min}$ for 28 cycles, followed by 41 cycles of $94^{\circ} \mathrm{C}$ for $1 \mathrm{~min}, 65^{\circ} \mathrm{C}$ for $1 \mathrm{~min}$, and $72^{\circ} \mathrm{C}$ for $1 \mathrm{~min}$ ) using the following primers: VEGFR-1: sense $5^{\prime}$-TGG GACAGTAGAAAGGGCTT-3', antisense 5'-GGTCCACTC CTTACACGACAA-3'. VEGFR-2: sense 5'-CATCACATCC
ACTGGTATTGG-3', antisense 5'-GCCAAGCTTGTACCA TGTGAG-3' . GAPDH: sense 5'-ATGGCACCGTCAAGGCT GAGA-3', antisense 5'-GGCATGGACTGTGGTCATGAG-3'.

Semi-automated analysis of PDGF-B gene expression by real-time quantitative reverse transcription $P C R$. After RNA extraction, cDNA was synthesized as described. PDGF-B RNA expression was quantified using the HT7900 sequence detection system (TaqMan, Perkin-Elmer Applied Biosystems, Foster City, CA, USA). The PCR reaction mixture contained $600 \mathrm{nM}$ of each primer and $200 \mathrm{nM}$ probe in a final volume of $22.5 \mu \mathrm{l}$. PCR conditions were at $50^{\circ} \mathrm{C}$ for $10 \mathrm{sec}, 95^{\circ} \mathrm{C}$ for $10 \mathrm{~min}$, followed by 40 cycles at $95^{\circ} \mathrm{C}$ for $15 \mathrm{sec}$ and $60^{\circ} \mathrm{C}$ for $1 \mathrm{~min}$. The following primers were used: Sense 5'-CTGG AGAGCTTGGCTCGTG-3', antisense 5'-GCGATCATGGC CGGC-3', 6-FAM-labeled 5'-AGAAGGAGCCTGGGTTCC CTGACCA-3'. As an internal control, $18 \mathrm{~S}$ expression was determined for every sample (Sigma-Aldrich Chemie GmbH, Munich, Germany). Relative gene expression levels were calculated using standard curves generated by serial dilutions of a cDNA mixture. Expression levels for each sample were divided by the $18 \mathrm{~S}$ expression level. Two independent analyses were performed for each sample and for each gene.

PDGF-B RNA induction by VEGF and bFGF. HUVECs were grown to $80 \%$ confluence in standard medium as described above, and medium was changed to $10 \%$ FCS-containing medium overnight. Cells were then incubated for various time-points in $0.5 \%$ FCS containing MEM (0.5\% MEM) with $20 \mathrm{ng} / \mathrm{ml} \mathrm{VEGF}$ and/or $20 \mathrm{ng} / \mathrm{ml} \mathrm{bFGF}$. In a different experiment, $80 \%$ confluent HUVECs were incubated for $24 \mathrm{~h}$ in $0.5 \% \mathrm{MEM}$, and then $20 \mathrm{ng} / \mathrm{ml}$ VEGF was added for incubation for various time-points. To determine the doseresponse, we incubated HUVECs in 10\% MEM overnight and then in $0.5 \%$ MEM containing increasing doses of VEGF for $24 \mathrm{~h}$. Total RNA was extracted, and the PDGF-B mRNA expression was analyzed using real-time PCR.

Effect of BIBF 1000 on VEGF-induced PDGF-B RNA expression. After incubation of HUVECs in $10 \%$ MEM overnight, the medium was changed to $0.5 \%$ MEM with $1 \mu \mathrm{M}$ BIBF 1000 or diluent. After 1 h, 20 ng/ml VEGF was added, and cells were incubated for $24 \mathrm{~h}$. After RNA extraction, PDGF-B expression was determined using real-time-PCR.

Effect of BIBF 1000 on VEGF signaling. Seventy-percent confluent HUVECs were incubated in 10\% MEM overnight. Subsequently, medium was changed to $0.5 \%$ FCS containing medium with/without $1 \mu \mathrm{M}$ BIBF 1000 . After $1 \mathrm{~h}, 20 \mathrm{ng} / \mathrm{ml}$ VEGF was added for an additional $15 \mathrm{~min}$. Cells were rinsed in PBS and protein was extracted from cell lysates by standard techniques. Western blot analysis was performed as described (7) using the polyclonal rabbit anti-phospho-p44/42 MAPK antibody (Cell Signaling Technology, Beverly, MA) and the anti-ß-actin antibody (Sigma).

Induction of PDGF-BB protein by VEGF and bFGF. HUVECs were cultured in standard medium up to $80-90 \%$ confluence. Then, medium was changed to $0.5 \%$ MEM containing $50 \mathrm{ng} / \mathrm{ml}$ VEGF and/or $50 \mathrm{ng} / \mathrm{ml} \mathrm{bFGF,} \mathrm{and} \mathrm{cells} \mathrm{were} \mathrm{incubated} \mathrm{for}$ 
$56 \mathrm{~h}$. After confirmation of cell viability $>95 \%$, the medium was collected, centrifuged, filtered through a $0.22-\mu \mathrm{m}$ membrane and stored at $-20^{\circ} \mathrm{C}(3)$. PDGF-BB protein expression was analyzed using ELISA assays (Quantikine, R\&D Systems) following the instructions provided by the manufacturer (3).

Induction of PDGF-B RNA expression by lung cancer-derived conditioned medium. CM from two human lung cancer cell lines (A549 and HTB-56) and HUVECs were prepared as described (3), and stored at $-20^{\circ} \mathrm{C}$ until use. Subsequently, subconfluent HUVECs were incubated in $10 \%$ FCS-containing medium overnight and then in lung cancer-derived $\mathrm{CM}$ for $4 \mathrm{~h}$ and $24 \mathrm{~h}$. RNA was extracted, and PDGF-B expression was determined by real-time PCR.

Effect of HUVEC-derived CM on A549 monolayer cell growth. Subconfluent HUVECs were cultured in $2 \%$ FCS containing MEM with/without $20 \mathrm{ng} / \mathrm{ml}$ VEGF. After $48 \mathrm{~h}$, the CM was collected. Human A549 lung cancer cells (4000 cells/well) were plated in 96-well plates. Following cell attachment, medium was changed to $2 \%$ MEM or HUVEC-derived CM. After 48 h, 3-[4,5-Dimethyl-thiazol-2-yl]2,5 diphenyltetrazolium bromide (MTT; Sigma, St. Louis, MO) was added to a final concentration of $0.5 \mathrm{mg} / \mathrm{ml}$, and cells were incubated for $90 \mathrm{~min}$. Medium and MTT were removed, dimethyl sulfoxide was added for $1 \mathrm{~min}$, and absorption was read at $570 \mathrm{~nm}$.

Migration of A549 cells treated with HUVEC-derived CM in vitro. Uncoated migration chambers (Becton Dickinson GmbH, Heidelberg, Germany) were seeded with 40,000 A549 cells in $2 \%$ FCS-containing medium. The bottom wells were filled with HUVEC-derived CM or $2 \%$ MEM supplemented with or without $20 \mathrm{ng} / \mathrm{ml}$ PDGF-BB. After $6 \mathrm{~h}$, the assay was stopped, non-migrated cells were removed, and migrated cells were fixed and stained using $0.2 \%$ crystalviolet (Merck, Darmstadt, Germany). Migrated cells were counted in five distinct areas at 100-fold magnification (18).

Statistical analysis. Experiments were performed at least in triplicate. All results are expressed as mean \pm standard error (SE). Data were analyzed using two-sided Student's t-test. Values of $\mathrm{p}<0.05$ were considered statistically significant.

\section{Results}

Time- and dose-dependent effects of VEGF and bFGF on $P D G F-B$ expression. Subconfluent HUVECs were treated with VEGF in $0.5 \%$ FCS containing medium for various times. Control cells were harvested at each time-point to exclude distortions from changes in culture conditions or cell confluence. VEGF induced PDGF-B RNA expression after $4 \mathrm{~h}$ and, significantly, after $24 \mathrm{~h}$ of incubation $(\mathrm{p}=0.08$ and $\mathrm{p}=0.03$, respectively, Fig. 1A). In a different approach, HUVECs were more thoroughly deprived of the effect of FCS by culturing them in $0.5 \%$ MEM for $24 \mathrm{~h}$. The subsequent addition of VEGF resulted in similar effects on PDGF-B RNA expression with a maximum after $4 \mathrm{~h}$ of incubation (data not shown). Further, HUVECs were incubated with increasing doses of VEGF up to $50 \mathrm{ng} / \mathrm{ml}$ for $24 \mathrm{~h}$. At a dose of $10 \mathrm{ng} / \mathrm{ml}$ VEGF,
A

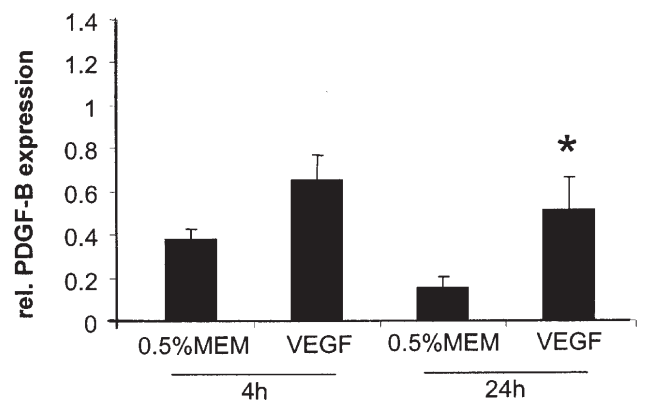

B

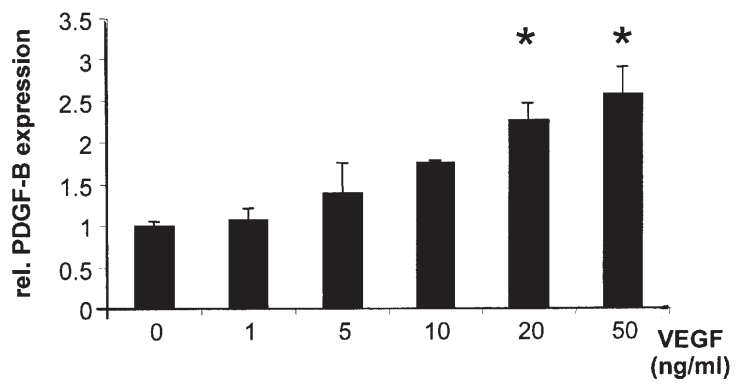

$\mathrm{C}$

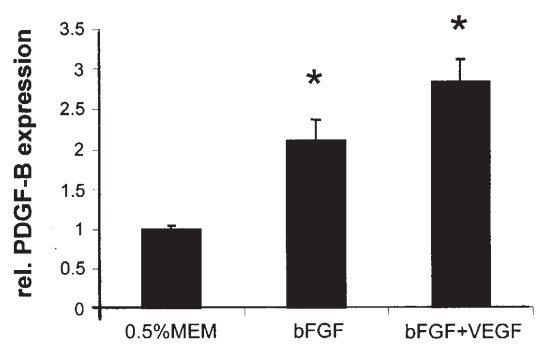

Figure 1. Induction of PDGF-B RNA expression by VEGF and bFGF. A, 80\% confluent HUVECs were cultured in 10\% MEM overnight. Subsequently, cells were incubated for 4 and $24 \mathrm{~h}$ in $0.5 \%$ MEM containing $20 \mathrm{ng} / \mathrm{ml}$ VEGF. Total RNA was extracted, and the PDGF-B mRNA expression was analyzed using real-time PCR. VEGF induced PDGF-B RNA expression after 4 and $24 \mathrm{~h}$ of incubation $(\mathrm{p}<0.05$ versus time-point 0 , Student's t-test; bars, mean \pm SE). B, after incubation in 10\% MEM overnight, $80 \%$ confluent HUVECs were cultured for $24 \mathrm{~h}$ in $0.5 \%$ MEM containing increasing doses of VEGF. There was a dose-dependent increase in PDGF-B RNA expression caused by the addition of VEGF ( ${ }^{*} \mathrm{p}<0.05$ versus time-point 0 ; bars, mean \pm SE). C, HUVECs were incubated in 10\% MEM overnight and then in $0.5 \%$ MEM with $20 \mathrm{ng} / \mathrm{ml} \mathrm{bFGF}$ and/or VEGF for $24 \mathrm{~h}$. After extraction of total RNA, the PDGF-B expression was determined. There was a significant increase in PDGF-B expression with the addition of bFGF ( $\mathrm{p}<0.05$; bars, mean $\pm \mathrm{SE}$ ). However, there was no significant additive effect of both VEGF and bFGF additions.

PDGF-B RNA expression increased markedly with further increase at incubation with a dose of $20 \mathrm{ng} / \mathrm{ml}$ VEGF (Fig. 1B).

Similarly to the results obtained with the addition of VEGF, bFGF also led to an increase of PDGF-B RNA expression in HUVECs with a maximum at an incubation time of $24 \mathrm{~h}(\mathrm{p}<0.05$, Fig. 1C). However, we observed no significant additive effect on PDGF-B expression with the addition of both VEGF and bFGF. As determined by ELISA, HUVECs treated with VEGF or bFGF secreted significantly more PDGF-BB protein than untreated cells ( $\mathrm{p}<0.01$, Fig. 2).

Effect of BIBF 1000 on VEGF-mediated PDGF-B induction. BIBF 1000 was used as an inhibitor of VEGF receptors in this 


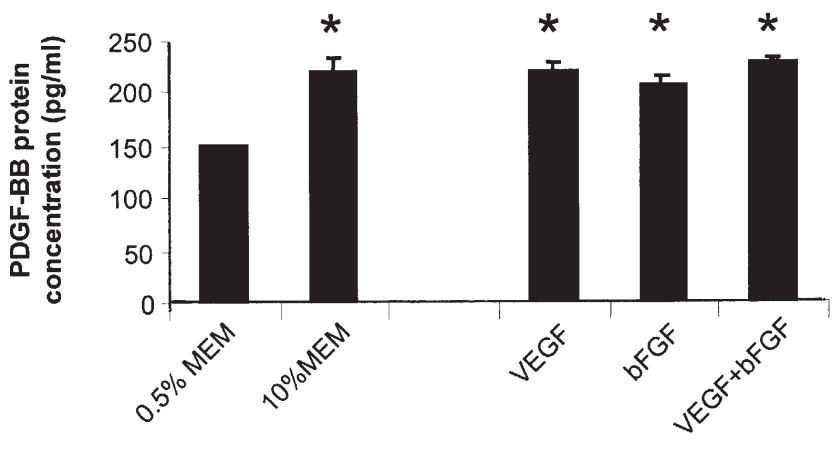

Figure 2. Induction of PDGF-BB protein by VEGF. Eighty percent confluent HUVECs were cultured for $56 \mathrm{~h}$ in $0.5 \%$ MEM containing $50 \mathrm{ng} / \mathrm{ml}$ VEGF and $/$ or $50 \mathrm{ng} / \mathrm{ml}$ bFGF. After confirmation of cell viability $>95 \%$, the medium was collected and analysed using ELISA assays. Secretion of PDGF-BB protein was significantly stimulated by the addition of either VEGF or bFGF to the medium ( $\mathrm{p}<0.01$ versus time-point 0 ; bars, mean $\pm \mathrm{SE}$ ).

A

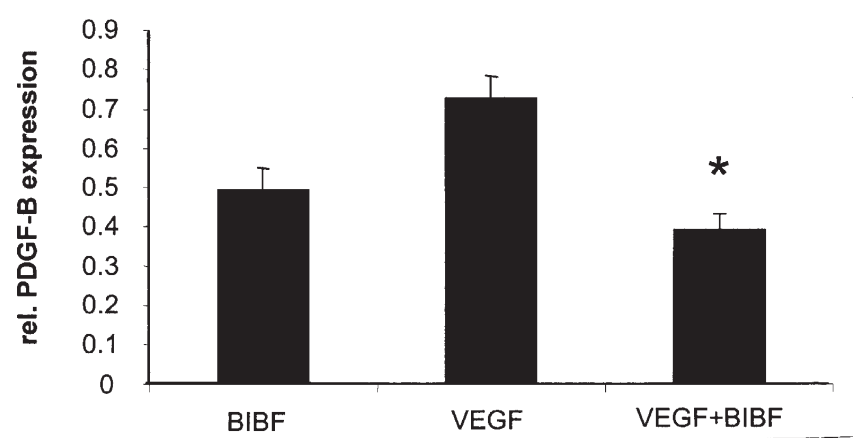

B

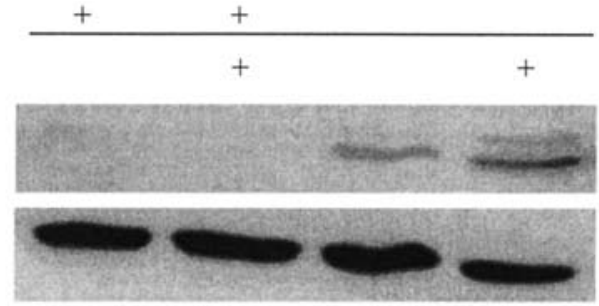

BIBF

VEGF

P-Erk

Actin

Figure 3. Blockade of VEGF-mediated PDGF-B induction by BIBF 1000. A, after incubation of HUVECs in 10\% MEM overnight, the medium was changed to $0.5 \%$ MEM with $1 \mu \mathrm{M}$ BIBF 1000 or diluent. After $1 \mathrm{~h}, 20 \mathrm{ng} / \mathrm{ml}$ VEGF was added, and cells were incubated for $24 \mathrm{~h}$. Addition of BIBF 1000 significantly inhibited PDGF-B RNA induction by VEGF ( ${ }^{*}<<0.01$; bars, mean $\pm \mathrm{SE})$. B, $60-70 \%$ confluent HUVECs were incubated with $1 \mu \mathrm{M}$ BIBF 1000 or diluent. After $1 \mathrm{~h}$, VEGF was added for 15 min. Protein was extracted and Western blot analysis performed. Activation of the MAP kinase pathway was markedly impaired with the addition of BIBF 1000

study. Pre-incubation of HUVECs with BIBF 1000 abrogated the effect of VEGF on PDGF-B RNA expression $(\mathrm{p}<0.01$, Fig. 3A). Cell viability was not obviously impaired during incubation with BIBF 1000. To confirm the blocking effect of BIBF 1000 on VEGF signaling, Western blot analysis was performed. While VEGF induced Erk $1 / 2$ phosphorylation in HUVECs, addition of BIBF 1000 blocked this effect (Fig. 3B).

Effect of lung cancer-derived conditioned medium on PDGF-B $R N A$ induction. Several lung cancer cell lines are known to

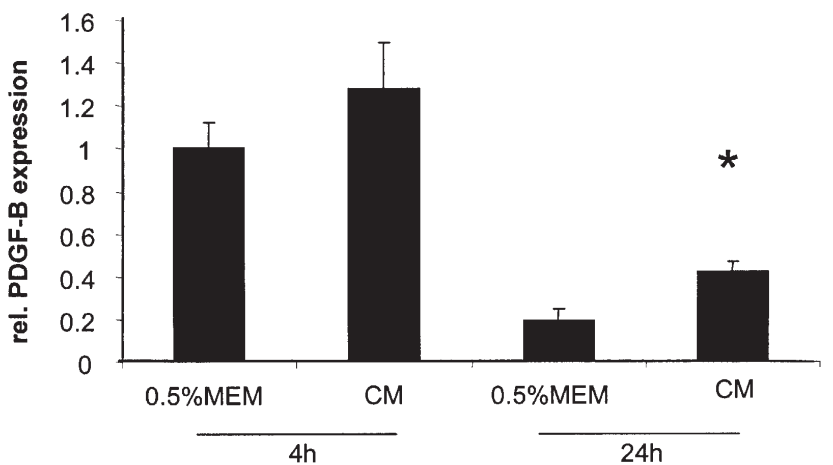

Figure 4. Induction of PDGF-B by lung cancer-derived conditioned medium. Conditioned medium (CM) was collected after culturing A549 lung cancer cells in $0.5 \%$ MEM for $48 \mathrm{~h}$. HUVECs were grown in 10\% MEM overnight and then for 4 and $24 \mathrm{~h}$ in $0.5 \%$ MEM or CM. Lung cancer-derived CM induced the expression of PDGF-B RNA dependent on the incubation time, which was significant after incubation for $24 \mathrm{~h}\left({ }^{*} \mathrm{p}<0.05\right.$; bars, mean $\left.\pm \mathrm{SE}\right)$.

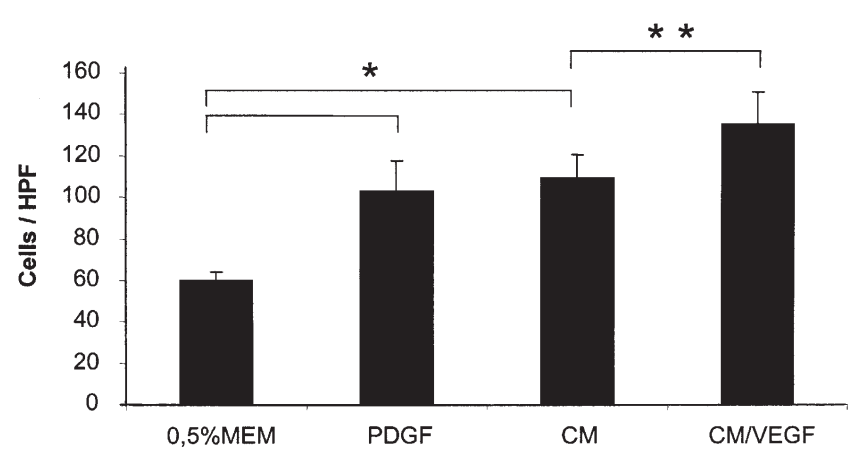

Figure 5. Stimulation of A549 lung cancer cell migration by HUVEC-derived conditioned medium. Conditioned medium (CM) from HUVECs was collected after incubation with or without VEGF for $48 \mathrm{~h}$ to induce PDGF-BB secretion in these cells. Subsequently, A549 lung cancer cells were seeded into migration chambers. The bottom wells were filled with HUVEC-derived CM or $2 \%$ MEM supplemented with or without $20 \mathrm{ng} / \mathrm{ml}$ PDGF-BB. After $6 \mathrm{~h}$, treatment with VEGF-stimulated $\mathrm{CM}$ resulted in a significant higher migration rate of A549 compared to the effect observed with normal unstimulated CM $\left({ }^{*} \mathrm{p}<0.05 ;{ }^{* *} \mathrm{p}=0.2 ;\right.$ bars, mean $\left.\pm \mathrm{SE}\right)$.

produce VEGF including A549 cells which were used in the following experiment (19). HUVECs were incubated with CM derived from A549 lung cancer cells which led to a significant increase in PDGF-B RNA expression (Fig. 4).

Effect of HUVEC-derived conditioned medium on A549 lung cancer cells in vitro. To further study the biological significance of the previous findings, HUVECs were incubated with or without VEGF and the CM was collected after $48 \mathrm{~h}$. According to our reported data, CM from HUVECs pre-treated with VEGF contained larger amounts of PDGF-BB (Fig. 2). This VEGF-stimulated CM resulted in a significant higher migration rate of A549 lung cancer cells compared to the effect observed with normal unstimulated CM (Fig. 5). Performing PCR, A549 cells showed no expression of VEGFR-1 and VEGFR-2 while HUVECs were used as a positive control (data not shown). In addition, there was a trend to enhanced monolayer growth when culturing A549 cells in stimulated CM versus unstimulated CM as determined by a MTT assay. However, this effect was not significant (data not shown). 


\section{Discussion}

In the present study, we provide evidence for an intense paracrine signaling between ECs, VSMCs and tumor cells. In particular, we explored factors that regulate the expression of PDGF-BB. With the exception of a few studies that have demonstrated the induction of PDGF-BB by various inflammatory cytokines such as TGFß-1 and IL-2 $(14,16)$, the regulation of PDGF-BB remains to be explored. Earlier, we demonstrated that VEGF is induced by tumor-cell derived PDGF-BB in various cell types effecting EC apoptosis (3). Hence, we postulated an opposite effect of VEGF on PDGF-BB induction in ECs in forms of a mutual induction loop. In HUVECs, VEGF caused a time- and dose-dependent increase in PDGF-B RNA and PDGF-BB protein expression. In addition, we also investigated the effect of bFGF on PDGF-BB induction. Comparable to the effect of VEGF, bFGF also induced PDGF-B gene and protein expression. However, there was no additive effect when HUVECs were stimulated with both VEGF and bFGF. Collectively, both VEGF and bFGF seem to contribute to PDGF-BB expression in ECs. Interestingly, similar results were detected with incubation of HUVECs in high concentrations of serum that is known to contain several growth factors including bFGF and VEGF $(20,21)$. These data are congruent to a previous study showing an increase in PDGF-A mRNA by serum due to activation of transcription (22). However, even small variations of growth factor concentrations may be of importance. Abramsson and associates provided evidence that not just the presence of PDGF-BB but rather an extracellular gradient adjacent to ECs is determining the recruitment of perivascular cells (23).

The novel indolinone derivative BIBF 1000 competitively binds to the ATP binding sites within the kinase domains of VEGFR1 through VEGFR3, FGFR1, FGFR3, and PDGFR $\alpha$ and $B$. Its in vitro effects on the inhibition of VEGF and bFGF signaling on multiple myeloma cells and their stromal microenvironment have recently been described (17). In the present study, addition of BIBF 1000 significantly antagonized the effect of VEGF on PDGF-BB induction in HUVECs. Further Western blot analyses demonstrated that the VEGFR signaling was effectively blocked by BIBF 1000 since it inhibited VEGF induced activation of the MAP kinase pathway. Therefore, therapy with agents directed against VEGF such as BIBF 1000 may also abrogate the paracrine effect of VEGF in addition to a direct effect on ECs (3).

To further investigate the biological mechanism of PDGF$\mathrm{BB}$ induction, we incubated HUVECs with CM derived from lung cancer cells that is known to contain multiple growth factors including VEGF and bFGF (24). This CM induced PDGF-B RNA expression, however, the overall induction of PDGF-B was less than with either VEGF or bFGF alone as previously demonstrated. Besides a lower concentration of these growth factors in the lung cancer cell-derived CM, the presence of antagonistic factors may be a possible explanation for these findings, as well. However, as a result of PDGF-BB induction by lung cancer cell-derived growth factors, ECs may exert further effects to stromal cells such as stimulation of migration of perivascular cells (25). These data support the current hypothesis of a modulating effect of cancer cells on ECs. In fact, the effect of tumor cell-derived CM on
ECs has been extensively studied largely demonstrating that malignant cells produce a host of growth factors that induce EC growth, inhibit EC apoptosis, and favour vascular permeability (26-28). Further, several groups defined the effect of cancer cell-derived VEGF on expression changes of endogenous VEGF and VEGFRs in EC monoculture (27). Collectively, tumor cells modulate ECs' functions by secretion of various growth factors thereby orchestrating angiogenesis.

Additionally, ECs may conversely also modulate A549 lung cancer functions, e.g. by induction of PDGF-BB. To test this hypothesis, we cultured lung cancer cells in HUVEC-derived CM. While there was no significant effect on lung cancer cell growth, HUVEC-derived CM significantly stimulated migration of A549 lung cancer cells. When HUVECs were pre-stimulated with VEGF, this stimulated CM further increased lung cancer cell migration. As demonstrated using ELISA assays, VEGF-stimulated CM contained larger amounts of PDGF-BB. A direct effect of VEGF on A549 cells could be excluded by demonstrating the lack of VEGFR expression on these cells. However, the difference of stimulated CM versus unstimulated CM was not significant, presumably because of the already marked effect of the unstimulated CM. Also, additional factors are likely to be involved. These novel data further support the hypothesis of a mutual interaction of cancer cells and ECs.

While the effect of ECs on cancer cells has not been described in more detail, some in vitro studies investigated the communication between bone cells and ECs demonstrating that there seems to be a reciprocal regulation between ECs and osteoblast-like cell lines. However, at least in one study, a direct cell-cell contact was necessary for an effect of ECs on osteoblast-like cells (29). Collectively, ECs may be important contributing members of the intricate communication pathways that link tumor and stromal cells via diffusible signaling molecules, and perhaps by direct cell contact-mediated mechanisms as well. In this regard, both PDGF-BB and VEGF are important growth factors in regulating angiogenesis and seem to be involved in an intense paracrine loop with reciprocal induction. Still, blocking receptors for both VEGF and PDGF-BB may be more effective in vivo than inhibition of a single receptor alone possibly by more efficiently interfering with the intercellular crosstalk (30). However, future developments of better therapeutic strategies will critically depend on a more thorough look into the intensive signaling loops involving tumor and stromal cells. Targeting key molecules may disrupt this signaling crosstalk which may result in alterations of biological functions of both stromal and tumor cells and potentially improve the therapeutic response.

\section{Acknowledgements}

S.R. contributed experiments to fulfill requirements for her MD thesis. This study was supported, in part, by the Dr Mildred Scheel Stiftung für Krebsforschung, Deutsche Krebshilfe (grant 10-2207-Re 1; to N.R.), the Deutsche Forschungsgemeinschaft grant Me 950-3-2 (to R.M.), and the Interdisciplinary Center of Clinical Research Muenster (IZKF Project Kess 2-023-04, to R.M. and T.K.). Frank Hilberg is a current employee of Boehringer Ingelheim Austria $\mathrm{GmbH}$, 
Vienna, Austria. Gerald J. Roth is a current employee of Boehringer Ingelheim Pharma GmbH \& Co. KG, Biberach an der Riss, Germany. For all other authors, there are no conflicts of interests.

\section{References}

1. Eberhard A, Kahlert S, Goede V, Hemmerlein B, Plate KH and Augustin HG: Heterogeneity of angiogenesis and blood vessel maturation in human tumors: implications for antiangiogenic tumor therapies. Cancer Res 60: 1388-1393, 2000.

2. Korff T, Kimmina S, Martiny-Baron G and Augustin HG: Blood vessel maturation in a 3-dimensional spheroidal coculture model: direct contact with smooth muscle cells regulates endothelial cell quiescence and abrogates VEGF responsiveness. FASEB J 15: 447-457, 2001.

3. Reinmuth N, Liu W, Jung YD, et al: Induction of VEGF in perivascular cells defines a potential paracrine mechanism for endothelial cell survival. FASEB J 15: 1239-1241, 2001.

4. D'Amore PA: Capillary growth: a two-cell system. Semin Cancer Biol 3: 49-56, 1992.

5. Ferrara N: Molecular and biological properties of vascular endothelial growth factor. J Mol Med 77: 527-543, 1999.

6. Clarke K, Smith K, Gullick WJ and Harris AL: Mutant epidermal growth factor receptor enhances induction of vascular endothelial growth factor by hypoxia and insulin-like growth factor-1 via a PI3 kinase dependent pathway. Br J Cancer 84: 1322-1329, 2001.

7. Reinmuth N, Liu W, Fan F, et al: Blockade of insulin-like growth factor I receptor function inhibits growth and angiogenesis of colon cancer. Clin Cancer Res 8: 3259-3269, 2002.

8. Nauck M, Roth M, Tamm M, et al: Induction of vascular endothelial growth factor by platelet-activating factor and plateletderived growth factor is downregulated by corticosteroids. Am J Respir Cell Mol Biol 16: 398-406, 1997.

9. Kawai T, Hiroi $\mathrm{S}$ and Torikata C: Expression in lung carcinomas of platelet-derived growth factor and its receptors. Lab Invest 77: 431-436, 1997.

10. Ostman A and Heldin $\mathrm{CH}$ : Involvement of platelet-derived growth factor in disease: development of specific antagonists. Adv Cancer Res 80: 1-38, 2001.

11. Schonherr E, Jarvelainen HT, Sandell LJ and Wight TN: Effects of platelet-derived growth factor and transforming growth factor-beta 1 on the synthesis of a large versican-like chondroitin sulfate proteoglycan by arterial smooth muscle cells. J Biol Chem 266: 17640-17647, 1991.

12. Benjamin LE, Hemo I and Keshet E: A plasticity window for blood vessel remodelling is defined by pericyte coverage of the preformed endothelial network and is regulated by PDGF-B and VEGF. Development 125: 1591-1598, 1998.

13. Lindahl P, Johansson BR, Leveen P and Betsholtz C: Pericyte loss and microaneurysm formation in PDGF-B-deficient mice. Science 277: 242-245, 1997.

14. Kamp H, Geilen CC, Sommer C and Blume-Peytavi U: Regulation of PDGF and PDGF receptor in cultured dermal papilla cells and follicular keratinocytes of the human hair follicle. Exp Dermatol 12: 662-672, 2003.
15. Hsu S, Huang F and Friedman E: Platelet-derived growth factor-B increases colon cancer cell growth in vivo by a paracrine effect. $\mathrm{J}$ Cell Physiol 165: 239-245, 1995.

16. Ebert M, Yokoyama M, Friess H, Kobrin MS, Buchler MW and Korc M: Induction of platelet-derived growth factor A and B chains and over-expression of their receptors in human pancreatic cancer. Int J Cancer 62: 529-535, 1995.

17. Bisping G, Kropff M, Wenning D, et al: Targeting receptor kinases by a novel indolinone derivative in multiple myeloma: abrogation of stroma-derived interleukin-6 secretion and induction of apoptosis in cytogenetically defined subgroups. Blood 107: 2079-2089, 2006

18. Reinmuth N, Liu W, Ahmad SA, et al: $\alpha \mathrm{v} B 3$ integrin antagonist S247 decreases colon cancer metastasis and angiogenesis and improves survival in mice. Cancer Res 63: 2079-2087, 2003.

19. Li X, Liu X, Wang J, et al: Effects of thalidomide on the expression of angiogenesis growth factors in human A549 lung adenocarcinoma cells. Int J Mol Med 11: 785-790, 2003.

20. Mortell KH, Marmorstein AD and Cramer EB: Fetal bovine serum and other sera used in tissue culture increase epithelial permeability. In Vitro Cell Dev Biol 29A: 235-238, 1993.

21. Kniss DA and Burry RW: Serum and fibroblast growth factor stimulate quiescent astrocytes to re-enter the cell cycle. Brain Res 439: 281-288, 1988.

22. Takimoto $\mathrm{Y}$ and Kuramoto A: Mechanism of regulation of PDGF-A chain gene expression by serum and TPA. Biochim Biophys Acta 1260: 176-182, 1995.

23. Abramsson A, Lindblom P and Betsholtz C: Endothelial and nonendothelial sources of PDGF-B regulate pericyte recruitment and influence vascular pattern formation in tumors. J Clin Invest 112: 1142-1151, 2003.

24. Volm M, Koomagi R, Mattern J and Stammler G: Angiogenic growth factors and their receptors in non-small cell lung carcinomas and their relationships to drug response in vitro. Anticancer Res 17: 99-103, 1997.

25. Ferns GA, Sprugel KH, Seifert RA, et al: Relative plateletderived growth factor receptor subunit expression determines cell migration to different dimeric forms of PDGF. Growth Factors 3: 315-324, 1990.

26. Castilla MA, Neria F, Renedo G, et al: Tumor-induced endothelial cell activation: role of vascular endothelial growth factor. Am J Physiol Cell Physiol 286: C1170-C1176, 2004.

27. Wang D, Donner DB and Warren RS: Homeostatic modulation of cell surface KDR and Flt1 expression and expression of the vascular endothelial cell growth factor (VEGF) receptor mRNAs by VEGF. J Biol Chem 275: 15905-15911, 2000.

28. Liu W, Davis DW, Ramirez K, McConkey DJ and Ellis LM: Endothelial cell apoptosis is inhibited by a soluble factor secreted by human colon cancer cells. Int J Cancer 92: 26-30, 2001.

29. Villars F, Bordenave L, Bareille R and Amedee J: Effect of human endothelial cells on human bone marrow stromal cell phenotype: role of VEGF? J Cell Biochem 79: 672-685, 2000.

30. Erber R, Thurnher A, Katsen AD, et al: Combined inhibition of VEGF and PDGF signaling enforces tumor vessel regression by interfering with pericyte-mediated endothelial cell survival mechanisms. FASEB J 18: 338-340, 2004. 